\title{
El Arbitraje Tributario Interno
}

\author{
Mario Alejandro Flor y Juan Carlos Peñafiel
}

\begin{abstract}
Sumario
1. Introducción. 2. El arbitraje y otros medios de resolución de conflictos en materia tributaria en el Ecuador. 2.1 Convenios tributarios. 2.2 Sistemas de estimación objetiva global. 2.3 Facilidades de pago. 3. Aspectos a superar para la aplicación del arbitraje tributario como mecanismo para la solución de conflictos internos. 3.1 Principio de legalidad y de reserva de ley. 3.2 Indisponibilidad de la obligación tributaria. 3.3 Exclusividad jurisdiccional. 4. Conclusión y reflexión.
\end{abstract}

\section{INTRODUCCIÓN}

La existencia del conflicto es natural a toda sociedad e inevitable desde que éste supone pretensiones contrapuestas respecto de bienes limitados. El objetivo perseguido para alcanzar un mayor grado de orden social no es la eliminación total del conflicto, sino la búsqueda de formas de controlarlo para lograr un grado razonable de equilibrio en las relaciones entre los miembros de una comunidad. ${ }^{1}$

Bajo esa realidad, la administración de justicia aparece como una pieza necesaria para dirimir los conflictos dentro de una sociedad y permitir la convivencia de quienes la conforman. No obstante, a mediados del siglo pasado una nueva realidad política económica ha irrumpido generando necesidades sociales que no

I. CAIVANO, Roque J., Arbitraje, Ad-Hoc, Buenos Aires, p. 21. 
encuentran respuestas satisfactorias en la ya clásica administración de justicia.

En los tiempos modernos, el problema de mantener la paz social se agrava: la creciente concentración de población en grandes ciudades, el incesante avance en la tecnología, un profundo incremento en las relaciones comerciales internacionales y la generación de nuevas necesidades sociales han provocado un aumento de los conflictos que ha desbordado las estructuras que el Estado provee para dirimirlos.

Como reacción natural, los países han comenzado a admitir y hasta fomentar la utilización de medios alternativos de solución de conflictos como herramienta que permite descomprimir la congestión en el sistema judicial y a su vez asegurar a los ciudadanos el acceso a una justicia eficiente, administrada por las mismas partes dentro de su esfera de libertad y en el marco de sus derechos disponibles.

En el escenario ecuatoriano hemos sido testigos como el contencioso - tributario ha aumentado de una manera significativa la cantidad de casos que debe conocer y resolver; una parte por el constante avance del derecho tributario y financiero pero otra muy importante por el desempeño de las administraciones tributarias que, si bien es cierto, han elevado sus niveles de recaudación y eficiencia en el cobro de las obligaciones tributarias de los contribuyentes, también, es preciso advertirlo, ha aumentado los litigios en un número importante, sin que la función judicial haya podido reaccionar en cumplimiento de los principios de celeridad $\mathrm{y}$ eficiencia.

El arbitraje es, en una primera aproximación, un método de solución de controversias mediante el cual, en ciertas ocasiones, la ley permite a los particulares sustraerse de la intervención de los órganos judiciales estatales ${ }^{2}$. Es una herramienta mediante la cual se resuelven los conflictos por particulares que no revisten la calidad de jueces estatales. ${ }^{3}$ 
Con el objetivo de establecer la naturaleza jurídica del arbitraje se han alzado diferentes voces que, a modo de síntesis, pueden ser agrupadas en tres teorías:

1. Por un lado, los que sostienen la naturaleza contractual del arbitraje ponen el acento en el carácter privado del instituto, tanto con relación a su origen como a la calidad de los árbitros. Esta tesis encuentra su principal argumento en la autonomía de la voluntad de las partes; por eso es que la relación entre éstas y el árbitro es eminentemente contractual. Su actividad se fundamenta en que siendo las cuestiones que se someten a arbitraje originadas en derechos disponibles por las partes, el Estado no puede privarlos de la facultad de escoger el mejor método para resolverlas.

Pero a su vez niegan que los árbitros ejerzan una función jurisdiccional, porque atento a su falta de imperium, la efectividad de sus decisiones arbitrales proviene del compromiso que ambas partes asumieron de acatarla, y no tiene, por ello, las características propias de una sentencia. $^{4}$

Por último, señalan que el laudo arbitral obliga a las partes en la misma forma que lo haría un contrato, gozando de la protección jurídica inherente a este último, razón por la cual se ha llegado a sostener que el árbitro es un agente de las partes y a asimilar su actuación a la de un mandatario.

2. Por otro lado, se encuentran los seguidores de la tesis procesal, quienes sostienen que los árbitros ejercen una verdadera función jurisdiccional, la cual no solo es atribuida por un acuerdo entre las partes, sino que es el pro-

2. FELDESTEIN DE CÁRDENAS, Sara - LEONARDI DE HERBÓN, Hebe M., El arbitraje, cit., p. 1

3. CAIVANO, Roque J., Arbitraje, cit., p. 47.

4. CAIVANO, Roque J., Arbitrajc, cit., p. 95 
pio Estado que a través de su ordenamiento jurídico reconoce a los árbitros su potestad jurisdiccional. De ello resulta que el arbitraje es un verdadero juicio y que el laudo tiene autoridad de una sentencia de última instancia.

3. Finalmente, con la intención de armonizar ambas concepciones, hay quienes reconocen en el arbitraje una fuente inmediata, el acuerdo de la voluntad de las partes (teoría contractual), y que a su vez los inviste con una función jurisdiccional. Caivano sostiene que estamos frente a una jurisdicción instituida por un negocio particular. ${ }^{5}$

Veamos entonces cómo la figura del arbitraje puede aprovecharse -o no- en el marco del derecho tributario bajo el contexto de la legislación ecuatoriana.

\section{El arbitraje y Otros medios de RESOLUCIÓN DE CONFLICTOS EN MATERIA TRIBUTARIA EN EL ECUADOR}

Si bien no existe en la historia ecuatoriana una aplicación directa del arbitraje en materia tributaria en los términos concebidos para el arbitraje comercial, sí existieron en nuestra legislación ciertos institutos en donde se aplicaba una negociación entre Estado y contribuyentes (generalmente con delegados de una industria o profesión específica) para definir tributos. Repasemos brevemente estos capítulos de la historia tributaria ecuatoriana:

\subsection{Convenios Tributarios}

El convenio tributario tuvo su aplicación en el Ecuador en dos etapas: una primera con el Código Fiscal publicado en el Re-

5. CAIVANO, Roque J., Arbitrajc, cit., p. 97.

118 Revista Ecuatoriana de Arbitraje 
gistro Oficial 400 de 25 de junio de 1963, con vigencia hasta el año 1975, año en el que el Código Tributario lo reemplazó; y una segunda en 1993, incorporado en la Ley de Régimen Tributario Interno.

Las características del primer convenio de los mencionados precedentemente, fueron las siguientes:

- Consistía en un acto administrativo que exigía para su eficacia la adhesión del contribuyente.

- Tenía un carácter transaccional diferente de la transacción prevista en el Código Civil.

- Debía versar exclusivamente sobre cuestiones de hecho de las que dependía la medida de la obligación tributaria; no podía referirse a asuntos de derecho.

- Servía para fijar la base de la liquidación de los impuestos y tenía lugar cuando no se podía establecer en forma cierta y determinada la obligación tributaria.

- Tenía una duración de tres años, a menos que se hubiere convenido por un tiempo menor.

- Era aplicable a todos los impuestos directos e indirectos, tanto nacionales como seccionales, excepto a los aduaneros.

- Podía celebrarse en cualquier tiempo antes de que el Tribunal Fiscal dictase sentencia, si es que la obligación era discutida.

De otra parte, la naturaleza del convenio tributario instaurado en su segunda etapa, a partir del año 1993, era de una determinación mixta de obligaciones tributarias, pues la determinación la realizaba el fisco una vez que el contribuyente 
presentaba información financiera, contable y empresarial, con la que se podía establecer las bases de imposición y la cuantía del tributo.

Una vez que se establecía las bases de imposición el contribuyente debía "adherirse" a efectos de perfeccionar el convenio, toda vez que uno de los requisitos establecidos por la normativa legal que regía este tipo de convenios, determinaba el cumplimiento de todos los requisitos y la adhesión del contribuyente como elementos condicionantes para su validez.

Las características del segundo convenio tributario que rigió en el Ecuador, fueron las siguientes:

- Consistía en una modalidad de la determinación mixta.

- Tenía carácter transaccional diferente de la transacción prevista en el Código Civil y para su eficacia debía cumplir los requisitos previstos en la ley y en los reglamentos.

- Se requería de la adhesión del sujeto pasivo.

- Era aplicable al Impuesto sobre la Renta, al IVA y al Impuesto a los Consumos Especiales, es decir a la porción medular de la imposición interna.

- Tenía una duración de hasta tres años, pudiéndose renovar por periodos iguales.

- Podía, durante su vigencia, modificarse o denunciarse de mutuo acuerdo cuando surgían nuevos elementos de juicio.

- Se preveía expresamente que se suscribirían previa negociación entre la administración y los contribuyentes y ante el incumplimiento de estos últimos se darían por terminados. 
- Para el Impuesto a la Renta se tomaría en cuenta las declaraciones de los tres años anteriores; las determinaciones efectuadas por la administración vía control; el capital utilizado y las ventas de los tres ejercicios inmediatamente anteriores; la rentabilidad existente en otras actividades similares; $y$ otros elementos a juicio de la administración.

- La determinación que surgía del convenio se tenía por definitiva y la administración no podrá efectuar fiscalización alguna.

Vemos como este instituto -en su primera y segunda etapas-, requería la "adhesión" del contribuyente para cumplir con todos los requisitos que la ley de aquella época establecía, especialmente para determinar, en la segunda etapa de su vigencia en el Ecuador -en forma mixta, con el Estado-el impuesto a la renta, impuesto al valor agregado e impuesto a los consumos especiales.

Es necesario indicar que la aplicación del convenio tributario, en su segunda etapa, no fue de todo feliz y dio lugar a abusos, que de a poco fueron detenidos mediante sentencias emitidas por la Corte Suprema de Justicia. Su vigencia fue breve y se lo derogó en el año 1996.

\subsection{Sistemas de Estimación Objetiva Global}

Otro de los institutos que tuvo vida jurídica en el Ecuador, en donde de alguna forma requería la concurrencia de la "negociación" de las partes de la relación jurídica tributaria, era el régimen denominado "Sistema de Estimación Objetiva Global".

El sistema de estimación objetiva global se implantó en Ecuador a fines de 1993 y luego de una duración efímera fue derogado en 1995. Fue aplicable a las personas naturales que ejercen activi- 
dades empresariales o profesionales y que por el capital empleado o por el monto de ventas anuales no están obligadas a llevar formalmente contabilidad, pero sí un registro de ingresos y egresos debidamente sustentado. Se preveía la formación de juntas mixtas integradas en forma paritaria por representantes de la administración y de los diferentes grupos de contribuyentes, las cuales tenían por finalidad establecer el importe global que por Impuesto a la Renta y por Impuesto al Valor Agregado debían satisfacer cada grupo y por repartición cada individuo.

Se trataba de una verdadera negociación entre los representantes de la administración tributaria y de los contribuyentes que mediante acuerdos, en forma aproximativa, efectuaban las determinaciones de las obligaciones tributarias. El representante de la administración que presidía la junta mixta respectiva tenía voto dirimente. En caso de discrepancia sobre los hechos cabía acudir a la comisión tributaria integrada de modo similar a las juntas, la cual en instancia única, así mismo con el voto dirimente del representante de la administración que la presidía, resolvía el diferendo 6 .

El sistema de estimación objetiva global no era obligatorio. Los contribuyentes podian presentar sus resultados anuales sobre la base de los registros que debían llevar. Inclusive, como es obvio, podian demostrar haber incurrido en pérdidas, lo cual no era factible si se acogían al sistema indicado. Lo que no cabía era en unos ejercicios declarar resultados y en otros acogerse a la estimación objetiva global. Una vez que el contribuyente se integraba al sistema de estimación objetiva global, debía continuar en él.

6. El sistema de estimación objetiva global no constituyó una solución p̣ara ampliar la masa de contribuyentes y sobre todo pata incorporar a la tributación a grupos que integran la cconomia informal, a pequeños empresarios que calificados de artesanos se acostumbraron a no pagar contribuciones y a los profesionales en libre cjercicio que tampeco lo han hecho. Hubo poca colaboración de las asociaciones gremiales y falta de una metodología cierta para que en cada rama de las actividades empresariales se efectuaran los estudios apropiados a fin de sentar las bases de la estimación. Además, fue muy discutible el que se extenciera el sistema al IVA. El tena de los contribuyentes menores continúa insoluto. 
La naturaleza de la estimación objetiva global no llegó a discernirse. No se definió si se trataba de acuerdo de carácter privado o un acto administrativo de adhesión. Hay más razones para pensar lo segundo por la preeminencia definitoria que se confirió a los presidentes de las juntas y de la comisión, los cuales debían ser representantes de la administración. En tal caso habría sido posible impugnar los resultados de la estimación objetiva global en sede contenciosa, distorsionándose de esa manera los objetivos que se tuvieron en mente al instaurarla. Respecto de la obligatoriedad de incorporarse al sistema, la jurisprudencia de casación se ha pronunciado en el sentido de que el hecho de integrarse o no al respectivo grupo era voluntario y que en caso de no hacerlo debía presentarse las declaraciones individuales.

\subsection{Facilidades de Pago}

Actualmente, si bien no existe una verdadera negociación de la cuantía de la obligación tributaria, el contribuyente puede proponer las fechas de pago en las que podría satisfacer la obligación tributaria determinada, interviniendo con su voluntad en uno de los elementos de negociación de cualquier método alternativo para la solución de conflictos: la oportunidad.

En efecto, en la fase recaudatoria, al tenor del Código Tributario, los deudores de obligaciones tributarias tienen el derecho a que se les conceda facilidades de pago. $\mathrm{Al}$ intento dirigirán a la administración la correspondiente petición con la oferta de satisfacer una parte de la deuda (que no puede ser inferior al $20 \%$ ), de someterse a un plan de pagos (regularmente con un plan máximo de seis meses y extraordinariamente con un plan máximo de dos años) y de garantizar el crédito fiscal hasta su cabal solución. La administración, cumplidos los requisitos, mediante la emisión de la respectiva resolución está obligada a conceder las facilidades solicitadas. La jurisprudencia ha reconocido este derecho de los deudores tributarios de diferir los pagos, así como el derecho de petición, inclusive en sede contenciosa, de las resoluciones que 
nieguen ese derecho. Es un caso claro de que la voluntad de los contribuyentes, puede incidir en la indisponibilidad de la obligación tributaria, al menos respecto de la oportunidad en que deba efectuarse la recaudación.

\section{Aspectos a superar para la aplicación del ar- BITRAJE TRIBUTARIO COMO MECANISMO PARA LA SO- LUCIÓN DE CONFLICTOS INTERNOS}

La aplicación del arbitraje en materia tributaria supone la superación de ciertos paradigmas en relación con importantes principios de la tributación como son el principio de legalidad y de reserva de ley, que en su clásica acepción podrían ser obstáculos para la implementación del arbitraje tributario; también cabe pronunciarse sobre la indisponibilidad de la obligación tributaria y su vinculación con el principio de actividad reglada, a través del cual se entiende tradicionalmente que es vetado para la administración disponer de los créditos fiscales, salvo-como lo veremosque se conceptualice a este último principio, y se le otorgue flexibilidad frente a las necesidades del mundo contemporáneo; $y$, finalmente, merece también análisis la facultad exclusiva de los órganos jurisdiccionales del Estado, cuya naturaleza de irrenunciable en materia de impuestos -por ser de orden estrictamente público-, será una característica que la corriente para establecer el arbitraje tributario debería vencer para integrarlo al sistema jurídico ecuatoriano.

\subsection{Principio de Legalidad y de Reserva de Ley}

La creación de tributos y de sus exoneraciones solo puede hacerse mediante ley, es decir, a través de un acto legislativo en la forma prevista en la Constitución. En materia tributaria, el principio de legalidad es la facultad de establecer, modificar o extin-

guir tributos, facultad que recae sobre el Estado de forma exclusiva. 
El principio de legalidad forma parte esencial de la normativa tributaria y guarda directa relación con el principio de reserva de ley. La concepción tradicional de este principio es que determinadas materias se deben obligatoria y únicamente establecer a través de una ley:

- el objeto imponible,

- los sujetos activo y pasivo,

- la cuantía del tributo o la forma de establecerla,

- las exenciones y deducciones,

- los reclamos y recursos.

Este principio, para los fines de aplicación del arbitraje tributario como mecanismo para solución de controversias a nivel local, puede concebirse desde un punto de vista riguroso o desde un punto de vista que ofrezca cierta flexibilidad, este último punto que favorecería la implementación del arbitraje motivo del presente artículo. Veamos lo que la doctrina reseña sobre estos principios:

Dietrich Jesch ${ }^{7}$ señala: “. ..la reserva de la ley sólo significa, originaria y fundamentalmente, que ciertos ámbitos sustantivos no pueden ser regulados de modo general sin el asenso y la colaboración del Parlamento. ...La historia de la reserva legal es la historia del creciente estrechamiento de la libre actividad de la Administración; el ámbito de acción del cual dispone, en especial el ámbito jurídicamente vacio, se reduce continuamente.". En el mismo sentido, Miguel Carbonell, indica que "la reserva de ley puede entenderse como la remisión que hace normalmente la Constitución y de forma excepcional la ley, para que sea tuna ley y no otra norma jurídica la que regule determinada materia. En otras palabras, se está frente a una reserva de ley cuando, por voluntad del constituyente o por decisión del legislador, tiene que ser una ley en sentido formal la que regule un sector concreto del ordenamiento jurídico. ${ }^{18}$

7. JESCH, Dietrich, Ley y administración. Estudio de la evolución del principio de legalidad, $1^{\mathrm{a}}$ ed, trad. de Manuel Heredero, Madrid, España, Instituto de Estudios Administrativos, 1978, pp. 133-137.

8. CARBONELL, Miguel, "Sobre la reserva de ley y su problemática actual", Vinculo Juridico. Revista de la Facultad de Derecho de la Universidad lutónoma de Zacatecas, México, No. 42, Abril - Junio 2000 , р. 33. 
Alvarado Esquivel afirma que a su juicio "Ia reserva de ley no se agota en la aprobación del hecho imponible, sino que -por su carńcter absoluto-dicha reserva debe también cubrir los elementos determinantes o configuradores de ese hecho, ya que de ellos depende que la obligación tributaria que surja de su realización, respete el principio constitucional de legalidad tributaria. Los elementos que integran el hecho imponible, tanto subjetivo como objetivo, y en relación con este último, a todos sus aspectos (temporal, espacial, material y cuantitativo), deben ser materia de reserva de ley..."

El Art. 301 de la Constitución del Ecuador señala:

Art. 301.- Sólo por iniciativa de la Función Ejecutiva y mediante ley sancionada por la Asamblea Nacional se podrá establecer, modificar, exonerar o extinguir impuestos. Sólo por acto normativo de órgano competente se podrán establecer, modificar, exonerar y extinguir tasas y contribuciones. Las tasas y contribuciones especiales se crearain y regularín de acuerdo con la ley.

No vamos ahora a determinar si las disposiciones constitucionales vigentes en el Ecuador permiten interpretar al principio de legalidad de un modo riguroso o flexible, tan solo queremos describir un aspecto importante a superar para que la figura del arbitraje tributario pueda aplicarse en el Ecuador. Varios académicos consideran que tal como está contemplado el principio de legalidad en la Constitución se podría interpretar que nos encontramos dentro de un régimen de legalidad flexible o relativo, que admitiría los medios alternativos y el arbitraje tributario sin que ello implique violentar las normas constitucionales que tutelan el régimen tributario.

Existen elementos de los tributos que $a b$ origine no se consideran regidos por el principio de reserva de ley, de allí que quepa afirmar que en el orden tributario no todo se encuentra establecido por ley y que solo algunos aspectos forzosamente si lo deben estar. En todo caso, una norma tributaria no es un proceso automático, pues una misma situación podrá apreciarse e interpretarse de diversas maneras. 
El Dr. Pablo Egas, en las Memorias de las XXII Jornadas Latinoamericanas de Derecho Tributario considera -refiriéndose a la Constitución Política de 1998, que sobre la reserva de ley no ha variado con la actual Constitución-, que en el Ecuador existe una reserva de ley relativa, en donde la adopción de métodos alternativos de solución de conflictos no miran a la potestad de creación sino a la potestad de aplicación de los tributos.

\subsection{Indisponibilidad de la Obligación Tributaria}

A través del principio de indisponibilidad de crédito tributario o de obligación tributaria, se establece que los elementos de la obligación tributaria no podrán ser alterados por actos o convenios entre particulares.

Esta regulación sobre la indisponibilidad del crédito tributario a que hace referencia el precepto anterior deja bien a las claras para todos los que intervienen en la relación jurídico-tributaria que los actos que formalicen con otras personas para nada pueden afectar a la Administración y, por tanto, ésta debe en todo caso atender exclusivamente a los elementos que configuran el tributo, tanto en su aspecto subjetivo como objetivo, sin que haya de tener en cuenta las variaciones que se hayan producido en esos elementos como consecuencia de los pactos celebrados por los contribuyentes con terceras personas.

Este principio de indisponibilidad de la obligación tributaria debe ser superado para la aplicación del arbitraje tributario en la medida que se considera al arbitraje como una decisión de particulares que afectan un orden público restringido a la Administración Tributaria en virtud del principio de actividad reglada.

Admitir la existencia de los medios alternativos de solución de conflictos y del arbitraje en particular es al menos aceptar que este principio no es absoluto y puede entendérselo en forma fle- 
xible. Los tradicionalistas encuentran en este principio el óbice más grande para la aplicación de un arbitraje tributario; en tanto que nuevas corrientes vienen tomando fuerza en esta última década, como lo señala el autor Mauricio Piñeros Perdomo ${ }^{9}$ quien considera que el tributo indisponible es aquel que ha sido liquidado por el contribuyente o por la Administración Tributaria a través de los distintos mecanismos establecidos por la ley lo cual le da un carácter de definitivo al no ser susceptible de acción o recurso alguno. Por lo tanto, frente a un conflicto entre la Administración Tributaria y el sujeto pasivo en razón a una duda razonable sobre la aplicación de la normativa vigente, una errónea interpretación de las pruebas disponibles o cualquier otra controversia donde esté en duda la legitimidad del acto administrativo, el arbitraje puede constituirse en una alternativa para resolver esos conflictos.

En definitiva, según lo concluye la Dra. Ángeles García Frías "la indisponibilidad es un instrumento de seguridad jurídica pero también es importante tomar en cuenta que el proceso aplicativo de la norma tributaria es un germen permanente de inseguridad y es por eso que no existe una sólida razón para postular una exclusión razonable de las fórmulas arbitrales en el ámbito tributario"10

Antes de cerrar este apartado sobre la indisponibilidad del crédito tributario, creemos conveniente revisar muy brevemente un nuevo criterio sobre este principio, defendido por el profesor García Novoa y López quien sostiene que este principio debe reformularse como un principio de disponibilidad legal del crédito tributario, convirtiéndose esta disponibilidad en objeto de la ley, correspondiéndole a esta decidir si se puede o no disponer del crédito y en que supuestos.

9. PIÑEROS, Perdomo Mauricio, Memorias de las XXII Jornadas Latinoamericanas de Derecho Tributario, Tomo II, p. 84.

10. GARClA, Frias Ángeles, Memorias de las XXII Jomadas Latinoamericanas de Derecho Tributario, Tomo II, p. 138. 


\subsection{Exclusividad Jurisdiccional}

Otro factor a superar es sin duda el de la exclusividad jurisdiccional como principio constitucional. Repasemos lo que nuestra Constitución señala sobre la función judicial dentro del capítulo de Participación y Organización del Poder:

Art. 167.- La potestad de administrar justicia emana del pueblo y se ejerce por los órganos de la Función Judicial y por los demńs órganos y funciones establecidos en la Constitución.

Según la norma constitucional citada, la potestad jurisdiccional corresponde exclusivamente a los jueces y tribunales, al tiempo que consagra expresamente lo que se ha venido a denominar aspecto positivo de la exclusividad, esto es, la atribución exclusiva de la jurisdicción a los únicos órganos estatales investidos de potestad para esto.

La potestad jurisdiccional, según lo sostiene Ana María Chocrón ${ }^{11}$ está constitucionalmente reservada al Poder Judicial o, si se prefiere, solo los jueces y tribunales pueden ejercer la potestad jurisdiccional en el sentido que ha sido desarrollado, lo que se explica sobre la idea de que "determinados actos de soberanía sólo pueden ser declarados por los tribunales o autorizados por los tribunales ${ }^{12 \prime}$. Ahora bien, esto no ha impedido que puedan encontrarse casos que contraríen el principio de exclusividad conforme a la formulación expuesta. Esto es algo que abiertamente ha reconocido la doctrina que no ha dudado a continuación en ofrecer ejemplos de esa circunstancia. Las palabras de Montero Aroca son clarificadoras a este respecto cuando dice que "teóricamente la exclusividad expresa algo de tal modo arraigado en la esencia del estado moderno que las Constituciones no podrían negarlo, pero prácticamente las negaciones han sido constantes $^{13}$. . La circunstancia apuntada ha requerido entonces una con-

11. ChoCrón, Ana Maria, La Exclusividad y la Unidad Jurisdiccionales como Principios Constitucionales en el Ord̛́cnamienı Juridico Español.

12. SERRANO ALBERCA, Josc Manucl y Amaldo Alcubilla, Eurique, Comentarios, cit, nota 12, p. 1879.

13. MONTERO AROCA, Juan, Derecho jurisdiccional 1 , cit, nota 24, p. 81 ; GONZÁLEZ MONTES, José Luis, Instituciones de derecho, cit., nota 1, p. 49, entre otros. 
formidad del privilegio del que goza la administración con la mencionada reserva de jurisdicción que, sin embargo, y a decir de la doctrina, se muestra insuficiente para discernir qué tipo de intervención administrativa en el ámbito jurisdiccional resultaría permitida y cuál por el contrario debiera ser erradicada.

Para atender qué posibilidades tienen el arbitraje tributario de introducirse en el sistema debemos primero establecer qué tipo de sistema jurídico impera en el Ecuador: Aquel sistema como el defendido por el argentino de Casás, en el que existe una irrenunciabilidad de la jurisdicción federal, siempre que se encuentre comprometido la soberanía, el interés y orden público o actos estatales emitidos en ejercicio del iure imperii -otros autores que participan de este criterio determinan, en resumen, que el ejercicio de la función jurisdiccional es de la reserva del Poder Público, siendo inconciliable la delegación de esta facultad en particulares-; o, un sistema jurídico flexible, en el que las disposiciones constitucionales y legales aceptan al arbitraje como legítimo mecanismo de solución de controversias. A este efecto, repasemos lo que señala el Art. 190 de la Constitución ecuatoriana:

Art. 190.- "Se reconoce el arbitraje, la medinción y otros procedimientos alternativos para la solución de conflictos. Estos procedimientos se aplicarán con sujeción a la ley, en materias en las que por su naturaleza se pueda transigir..."

De su parte, el Art. 1 de la Ley de Arbitraje y Mediación menciona:

"El sistema arbitral es un mecanismo alternativo de solución de conflictos al cual las partes pueden someter de muttuo acuerdo, las controversias susceptibles de transacción, existentes of futuras para que sean resueltas por los tribunales de arbitraje administrado o por árbitros independientes que se conformaren para conocer dichas controversias."

Lo cierto es que el ingente número de asuntos tributarios sujetos a la resolución de la administración interna, municipal y 
aduanera, sin contar con las administraciones de excepción, que pueden adoptar posiciones apegadas a la recaudación y no al derecho, ocasionan que la administración de justicia se vea sometida en igual medida a una enorme cantidad de casos que deben resolver, convirtiendo la atención de esos casos en asuntos de prolongada duración.

Las corrientes modernas y las mismas necesidades de la comunidad advierten que en el campo tributario, al igual que en otros, es menester el uso de los medios alternativos de solución de conflictos, particularmente del arbitraje, como opera por ejemplo la República de Venezuela, la que teniendo similares garantías constitucionales, ha dado un paso adelante en la resolución de conflictos tributarios.

La Constitución venezolana de 1999 señala que "la potestad de administrar justicia emana de los ciudadanos" y que "los medios alternativos de justicia", así como "los ciudadanos que participan en la administración de justicia conforme a la ley", forman parte del sistema de justicia en Venezuela (artículo 253 de la Constitución).

Por aplicación de estas disposiciones constitucionales, el arbitraje, como medio alternativo de resolución de conflictos y los ciudadanos que actúan como árbitros, forman parte del sistema de administración de justicia en Venezuela. Esto fue un cambio fundamental con respecto a la Constitución de 1961, según la cual el Poder Judicial se ejercía únicamente a través de los Tribunales.

\section{ConClusión y Reflexión}

En conclusión, la demora excesiva en las decisiones de los tribunales contencioso-tributarios es un problema que afecta el interés de la Administración y del contribuyente. La incertidumbre del contribuyente ante la falta de decisión y el diferimiento indefinido del cobro del tributo ocasiona perjuicios al administrado y 
a la Administración. En el Presupuesto del Estado aparecen, año tras año, considerables cantidades de dinero por supuestos créditos tributarios pendientes de decisión en los tribunales, muchos de los cuales no podrán ser cobrados, bien porque la decisión favorezca finalmente al contribuyente o si favorece a la Administración, la posibilidad de ejecutar la decisión está disminuida. En situación similar se encuentra el contribuyente, quien tarda años en lograr una decisión sobre sus reclamaciones tributarias. Existe, por tanto, una necesidad de innovación, de búsqueda de nuevas fórmulas para la solución de controversias. La jurisdicción arbitral podría responder a esta necesidad de justicia, al permitir decidir con rapidez y eficacia las controversias tributarias.

La doctrina que aboga por permitir el arbitraje en materia tributaria ha señalado como requisitos para su procedencia, los siguientes, los cuales podrían implementarse en el Ecuador realizando reformas legales que viabilicen una importante opción para destrabar los asuntos tributarios controvertidos:

- que el arbitraje tributario esté previsto en la ley,

- que se establezca claramente lo que puede ser sometido a arbitraje,

- que se prevean las condiciones precisas de integración del tribunal arbitral,

- que se establezcan los efectos del laudo arbitral y su ejecución,

- y que sea un arbitraje de derecho.

La evolución del derecho tributario y la importante cantidad de conflictos en esta materia, hacen que el Ecuador deba plantearse la necesidad de adherirse a la línea de aceptar los medios alternativos de solución de controversias y particularmente el arbitraje, para resolver los conflictos tributarios que más se adecuen a la naturaleza de la intervención arbitral, para lo cual será necesario realizar las reformas legales pertinentes. 